\title{
Getting to 2020: A Clinical Review of the Diagnosis, Treatment and Prevention of Trachoma
}

\author{
Kian Madjedi, MA ${ }^{1}$; Ahmed Isam²; Curtis Sorgini, MD, FRCSC \\ ${ }^{1}$ Faculty of Medicine, Northern Ontario School of Medicine \\ ${ }^{2}$ Faculty of Medicine, University of Khartoum \\ ${ }^{3}$ Sorgini Eye Institute, Sudbury, Ontario
}

\section{A B STRACT}

\begin{abstract}
Objectives: The goal of this clinical review is to undertake a review of the literature to provide information to clinicians and trainees about the epidemiology, diagnosis, treatment and (most importantly) prevention of trachoma-the leading infectious cause of blindness worldwide. This review also serves to highlight the "SAFE" Strategy (Surgery, Antibiotics, Facial Cleanliness, and Environmental Improvement), which comprises the key trachoma treatment and prevention framework endorsed by the World Health Organization (WHO).

Methods: English articles were retrieved from the following databases: Medline, Clinical Key, the Cochrane Collaboration, the Association for Research in Vision and Ophthalmology, and the National Institute of Health Clinical Trials Database, using the following MeSH terms: trachoma, infectious eye disease, chlamydia trachomatis, SAFE, community prevention. Information originating from international public health agencies, as well as evaluation reports on the success of both community-based and international treatment and prevention programs were prioritized.

Conclusions The diagnosis of trachoma is typically a clinical one, and is made by identifying the key clinical signs of conjunctival inflammation and scarring, trichiasis and corneal opacification, especially in the context of a trachoma-endemic region. Discussion of the pathology and epidemiology of trachoma, as well as an evaluation of the overall success in the treatment and prevention of the disease is especially important as the WHO's target trachoma elimination year of 2020 approaches.
\end{abstract}

\section{RÉ S U MÉ}

Objectifs: Le but de cette revue clinique est d'entreprendre une revue de la littérature afin d'informer les cliniciens et les étudiants de l'épidémiologie, du diagnostic, du traitement et, plus que tout, de la prévention du trachome - la principale cause infectieuse de cécité à l'échelle mondiale. Cette revue sert aussi à souligner la stratégie " CHANCE » (Chirurgie, Antibiothérapie, Nettoyage du visage, Changement de l'Environnement), qui comprend à la fois le traitement clé du trachome et le cadre de prévention approuvés par l'Organisation Mondiale de la Santé (OMS).

Méthodes: Des articles en anglais ont été extraits à partir des bases de données suivantes : " Medline ", "Clinical Key ", la Collaboration Cochrane, "Association for Research in Vision and Ophthalmology " et " National Institute of Health Clinical Trials Database ", en utilisant les termes MeSH suivants (en anglais) : trachome, maladie infectieuse de l'œil, chlamydia trachomatis, CHANCE, prévention communautaire. L'accent a été placé sur l'information provenant d'agences internationales de santé publique, ainsi que de rapports d'évaluation sur le succès de programmes de traitement et de prévention communautaires et internationaux.

Conclusions: Le diagnostic du trachome est habituellement un diagnostic clinique, et se base sur les signes cliniques clés suivants : I'inflammation et la cicatrisation conjonctivale, le trichiasis, et l'opacification de la cornée, particulièrement lorsqu'on les retrouve dans une région où le trachome est endémique. Il est particulièrement important de discuter de la pathologie et de l'épidémiologie du trachome, ainsi que d'évaluer la réussite globale du traitement et de la prévention de cette maladie, puisque la date cible pour l'élimination du trachome par l'OMS en 2020 approche à grands pas.

\section{INTRODUCTION}

Trachoma (also known as granular conjunctivitis and Egyptian ophthalmia), is the leading infectious cause of ocular infection and blindness worldwide, affecting over 80 million individuals [1]. Trachoma is a form of conjunctivitis caused by repeated infections with the gram-negative bacteria Chlamydia trachomatis, which can lead to conjunctival scarring, tarsal distortion, and the subsequent inward turning of the eyelashes (trichiasis), leading Keywords: Opthalmology; Infectious Disease; Trachoma to abrasion of the cornea. Along with the loss of conjunctival goblet cells and resultant dysfunctional tear syndrome, this can result in an irreversible form of blindness [2].

Largely eradicated in most socioeconomically developed nations, trachoma tends to affect marginalized and resource-deficient individuals in developing countries [2]. Its transmission is closely associated with poor hygiene, and thus the condition typically predominates in regions with inadequate access to water and good 


\section{Review \& Clinical Practice}

sanitation $[1,3]$.

The World Health Organization (WHO) identifies trachoma as an avoidable cause of blindness, and as such, endorses systematic and coordinated efforts focusing on all levels of prevention [4]. Strong prevention efforts and rapid treatment of existing disease are the cornerstones of the WHO Alliance for Global Elimination of Trachoma by 2020: the "GET 2020" campaign. GET 2020 endorses "SAFE", a four-pronged approach to trachoma prevention and management that focuses on the importance of Surgical Intervention, Antibiotics, Facial Cleanliness, and Environmental Improvement strategies [4].

\section{METHODS}

English articles were retrieved from the following databases: Medline, Clinical Key, the Cochrane Collaboration, the Association for Research in Vision and Ophthalmology, and the National Institute of Health Clinical Trials Database, using the following MeSH terms: trachoma, infectious eye disease, chlamydia trachomatis, SAFE, community prevention. Information originating from international health agencies, as well as evaluation reports on the success of both community-based and international treatment and prevention programs were prioritized for selection.

\section{EPIDEMIOLOGY}

Trachoma is presently endemic in 54 countries and is most commonly found in developing nations across the African continent, the Middle East, Latin America and in remote communities across Australia [2]. Over 40 million people have active trachoma [3]. Of these, 7 million have active trichiasis and an additional 1.3 million are affected by the blinding sequelae of trachoma [1,3]. The highest prevalence of trachoma is found in northeast Africa, where in some regions the active disease affects more than $50 \%$ of the population under ten years of age [1]. Infection with the causative organism is typically seen in pediatric patients, with disease incidence peaking in children between four and six years of age. It is notable that children are most likely to develop active trachoma, while adults are more likely to experience blindness as the result of repeated infection and sequential worsening of the disease over time [5]. This is likely because trachoma-related blindness is a consequence of inflammation resulting from the immune response to the infection occurring over many episodes [5]. In certain hyper-endemic regions, however, such as presentday South Sudan, cicatricial complications of the disease may be seen at an earlier age than what might be typically expected [6]. One study identifies that $3 \%$ of children under fifteen years of age may be affected by the cicatrical complications of trachoma in regions where the population prevalence of active trachoma exceeds $80 \%$ [6].
Women are disproportionately affected by trachoma; the demographic distribution of trachoma prevalence affects nearly six times the number of women than it does men [5]. This has been explained by the increased likelihood of women having ongoing and intimate contact with children who may be infected with $C$. trachomatis [5].

Trachoma is a disease which clusters at the level of the community and within households [7]. Infection is typically spread through close personal contact, and by eye-seeking flies of the species Musca sorbens, which are attracted to pus, mucus, open sores and ocular secretions $[8,9]$. Secretions around the eyes have consistently been associated with increased rates of infection, as have crowded living conditions $[8,9]$. Poor personal hygiene and low levels of community sanitation have been identified as primary factors supporting the transmission of $\mathrm{C}$. trachomatis $[9,10]$. The disease is commonly spread from infected ocular or nasal secretions on fingers or through eye-to-eye contact such as that which might occur in close-quarters sleeping arrangements, as well as through indirect means such as the sharing of facecloths [11]. It is important to note that prolonged contact with infected individuals is necessary for the transmission of $C$. trachomatis [2].

\section{PATHOLOGY}

Trachoma is caused by infection with the A, B, Ba and C immunotypes of $C$. trachomatis; a gram-negative bacteria of the same genus that can cause genital infections (which occur with infection with the $\mathrm{D}$ through $\mathrm{K}$ types) [2]. C. trachomatis is an intracellular bacteria, and as such, is unable to replicate outside of a host cell. It survives in the extracellular environment in an inactive form; it is only when it attaches to the host's epithelial cells and is internalized that it begins to differentiate into its active form [2].

Repeated episodes of infection carry an increased risk of conjunctival inflammation, which can result in scarring in the subtarsal conjunctiva. Long-term conjunctival scarring can lead to the inward turning of the upper eyelids (a process known as 'entropion'). This can lead to the eyelashes physically touching and abrading the cornea, which can give rise to trichiasis. Eventually these multiple insults to the cornea (along with the loss of conjunctival goblet cells and resulting tear film dysfunction) can lead to corneal opacification [2]. Corneal scarring usually develops slowly and over many years. The importance of repeated infection is reaffirmed here in the pathogenesis of trachoma; blindness from the disease rarely results from a single episode of infection [5].

Children infected with $C$. trachomatis tend to have higher bacterial loads than adults and tend to have longer durations of infection. This is likely a product of the acquired immune response 


\section{Review \& Clinical Practice}

developed by adults over the course of repeated infection. Despite the decreased duration of infection, adults are more likely to develop more intense conjunctival scarring (and therefore a higher likelihood of developing trichiasis) as the result of cumulative infectious damage [5].

\section{CLINICAL MANIFESTATIONS \& DIAGNOSIS}

The clinical manifestations of active trachoma result from chronic inflammation of the conjunctiva and include the following: the appearance of follicles (subepithelial accumulations of small yellow elevations), papillae surrounding the follicles, and the enlargement and thickening of small vessels in the conjunctiva [12]. Other symptoms include the general signs of any other type of conjunctivitis: discomfort or pain, photophobia, and erythema [2]. A pathognomonic sign of trachoma is the presence of Herbert's pits; depressions in the upper margins of the cornea resulting from the resolution of conjunctival follicles [2]. These clinical manifestations are true for all forms of active trachoma and are not as common in chronic or asymptomatic trachoma. It is important to note that most individuals with active infection often tend to be asymptomatic $[2,13]$.

A simplified trachoma grading system (STGS) was developed in 1987 by the WHO to aid in the rapid diagnosis of trachoma at the community level (see Table 1) [12]. This grading system classifies the severity of the infection on a scale of 1-5 and is widely used in international trachoma surveillance and treatment programs [4].

\section{Ocular Examination}

An ocular examination should be performed with at least $2.5 \mathrm{x}$ magnification and a strong light. The conjunctiva should be evaluated for discharge or inflammation, and it should be noted whether eyelashes rub against the cornea. The conjunctival fornices should be evaluated for foreshortening, as this finding may be identified in advance of more significant conjunctival scarring. A physical examination of the eye should also include an evaluation of the corneas for inflammation and opacification. As the process of entropion tends to preferentially affect the upper eye lid, this should be reflected upwards in order to better visualize the tarsal conjunctiva for evidence of follicles, inflammation, or scarring $[4,12]$.

\section{Diagnosis}

The diagnosis of trachoma is ultimately based on the clinical manifestations of the disease, and the findings from the examination of the eye can be used to categorize the disease according to the WHO classification [4,12]. Laboratory testing (including PCR and cytology) are typically confirmatory but are not widely

Table 1: World Health Organization Trachoma Simplified Grading Card (Modified from [12])

Classification

\begin{tabular}{|l|l|}
\hline $\begin{array}{l}\text { Trachomatous inflamma- } \\
\text { tion (follicular) TF }\end{array}$ & $\begin{array}{l}5 \text { or more follicles of }>0.5 \mathrm{~mm} \text { on } \\
\text { the upper tarsal conjunctiva }\end{array}$ \\
\hline $\begin{array}{l}\text { Trachomatous inflamma- } \\
\text { tion (intense) TI }\end{array}$ & $\begin{array}{l}\text { Papillary hypertrophy and inflam- } \\
\text { matory thickening of the upper } \\
\text { tarsal conjunctiva, obscuring more } \\
\text { than 50\% of the deep tarsal vessels }\end{array}$ \\
\hline $\begin{array}{l}\text { Trachomatous conjuncti- } \\
\text { val scarring (TS) }\end{array}$ & $\begin{array}{l}\text { Grossly visible scars in the tarsal } \\
\text { conjunctiva }\end{array}$ \\
\hline $\begin{array}{l}\text { Trachomatous trichiasis } \\
\text { (TT) }\end{array}$ & $\begin{array}{l}\text { 1 or more ingrown eyelashes touch- } \\
\text { ing the globe, or evidence of epila- } \\
\text { tion (eyelash removal) }\end{array}$ \\
\hline Corneal opacity (CO) & $\begin{array}{l}\text { Presence of corneal opacity blurring } \\
\text { part of the pupil margin }\end{array}$ \\
\hline
\end{tabular}

available in the low-resource settings in which trachoma is typically found [2].

\section{THE SAFE STRATEGY}

In 1998, The Alliance for the Global Elimination of Trachoma (under the aegis of the WHO) established a global initiative for the elimination of all causes of avoidable blindness by the year 2020 [4]. Trachoma was one of the five priority diseases identified as part of this initiative. The WHO, in collaboration with various nongovernmental organizations, has designed a program intended to eliminate blinding trachoma through a four-component strategy known as SAFE. The first two elements of the strategy (Surgery and Antibiotics) may be understood as the direct treatment of the disease through surgical procedures and pharmacotherapy, while the second two elements (Facial cleanliness and Environmental improvement) refer more generally to a set of public health approaches that may help prevent the spread of the disease.

\section{Treatment: Surgery \& Antibiotics}

Infection with $C$. trachomatis does not itself lead to blindness in all cases; rather, individuals for whom infection has been frequent and repeated may be at an elevated risk of blindness due to chlamydia-related trichiasis [1]. Surgery is the most direct way to prevent blindness from trichiasis [14]. Bilamellar tarsal rotation is the surgical treatment of choice, wherein an incision is made parallel to the eyelid margin and the eyelid is rotated outwards and sutured in a fashion to ensure the eyelid and eyelashes are no longer in contact with the cornea [14]. Despite the effectiveness of surgical intervention, there exist substantial barriers 


\section{Review \& Clinical Practice}

to its implementation and uptake. Studies have indicated that even when surgery is provided at no charge, patients are often unaware of the availability or benefits of surgery or are unable to afford transportation to the surgical site [15-17].

The medical treatment of trachoma recommended by the WHO is azithromycin, administered once annually at a dose of $20 \mathrm{mg} /$ $\mathrm{kg}$ [18]. Topical tetracycline (1\%) taken twice daily has also been shown to be equally efficacious, and is suggested as an alternative in areas where azithromycin is unavailable. A single dose of oral azithromycin has been found to be as effective as a long course of topical tetracycline for active trachoma [18-19]. Although tetracycline is widely available, compliance rates are often low due in part to undesirable side effects including a stinging sensation and temporarily blurred vision [18]. Azithromycin, in contrast, is well-tolerated and is associated with higher compliance and fewer adverse effects compared with tetracycline [18]. In communities where the prevalence of trachoma among children aged 1-9 years is greater than $10 \%$, evidence supports the use of mass antibiotic treatment with azithromycin in particular [19].

As with the administration of any antibiotic over long periods of time, there have been concerns about the possibility of resistance. While studies have documented azithromycin resistance in the $\mathrm{D}$ through $\mathrm{K}$ immunotypes associated with urogenitial infection, evidence suggests there is no significant increase in resistance after treatment for ocular $C$. trachomatis in endemic regions [20]. In light of these reassuring findings, the importance of incorporating ongoing surveillance for resistance as part of azithromycin-distribution trachoma programs has been emphasized, as the development of macrolide resistance would pose substantial challenges for the global elimination of trachoma [20].

\section{Prevention: Facial Cleanliness \& Environmental change}

While the surgical and medical treatment of the complications of trachoma can be highly effective, it is important to recognize that the blindness associated with trachoma results from repeated infection with $C$. trachomatis. The SAFE strategy endorses the notion that public health and preventive approaches aimed at decreasing the transmission of $C$. trachomatis can play an important role in helping decrease the incidence and prevalence of trachoma at the population level [21]. A strategy focused on reducing individual and community risk factors should thus be considered integral to any effort at controlling the spread of disease [21-22]. This is mostly likely to occur in response to effective implementation of the F and E components of SAFE [21].

Evidence strongly suggests that individuals with clean faces clear of visible ocular and nasal discharge are far less likely to have active trachoma [23]. This is of particular importance because fa- cial cleanliness is an easily modifiable risk factor. It has yet to be demonstrated, however, that face washing alone is directly associated with a decrease in trachoma prevalence [23]. Emerson et al. explain that increasing water supply and quality, improving access to latrines, reducing crowding within households, providing health education, and decreasing the density of eye-seeking flies should decrease the transmission of trachoma [24]. Research examining the use of insecticide to control the population of eyeseeking flies is contradictory; some studies have shown a statistically significant decrease in the prevalence of active disease while other studies have found no difference [13, 23]. Evidence to support the role of latrines in directly controlling transmission is similarly inconclusive $[23,25]$.

Despite often contradictory studies, it is arguable that an increase in the quality and quantity of preventive strategies and community health education would play a considerable role in the overall control of disease transmission. While evidence is not available to directly support a causal relationship between specific preventive approaches and reduced disease transmission, the argument can be made that preventive approaches could (and should) still play an important role in combatting the spread of trachoma. The impact of preventive efforts would likely occur in concert with the other elements of the SAFE program to help decrease trachoma transmission and overall incidence [11].

Recently emergent approaches in the prevention of trachoma have been directed at providing health education at the community level, and providing training for paraprofessional community health workers to lead trachoma prevention strategies in their own communities [22]. Examples of such initiatives include increasing facial hygiene education and face cloth distribution for school-aged children, providing training to paraprofessionals on the dosing and administration of azithromycin, and providing financial support through microfinance for a community member to establish a business selling homemade soaps for face-washing $[22,26]$. Though evidence supporting these initiatives is at this point largely anecdotal, community-directed innovation in leading trachoma prevention initiatives may have the potential to play a key role in future preventive efforts, and should not be discounted.

\section{CONCLUSION}

Trachoma is the leading infectious cause of blindness worldwide, with repeated $C$. trachomatis infection leading to conjunctival scarring, trichiasis, and ultimately corneal opacification. This disease is particularly amenable to prevention efforts, which when implemented successfully, may help decrease the transmission and overall incidence of trachoma. The particular responsiveness of trachoma to surgical and medical treatment as well as environmental risk factor prevention place this condition at the nexus 


\section{Review \& Clinical Practice}

of curative and preventive medical work. The initiatives undertaken to date have highlighted the importance of strengthening local public health systems, as well as the success that can come from community engagement in trachoma elimination strategies [27]. It is reaffirming that several countries have recently reported having reached WHO elimination treatment targets [4]. These successes illustrate that trachoma elimination is indeed possible and a goal towards which medical and preventive care should continue to strive as we near closer to the target elimination year, 2020.

\section{REFERENCES}

1. Resnikoff S, Pascolini D, Etyaale D. Global data on visual impairment in the year 2002. Bulletin of the WHO. 2004;82(1):844-51.

2. Hu V, Holland M, Burton M. Trachoma: Protective and Pathogenic Ocular Immune Responses to Chlamydia trachomatis. PLoS Negl Trop Dis. 2013;7(2):2020.

3. Hu V, Harding-Esch E, Burton M, et al. Epidemiology and control of trachoma: systematic review. Trop Med Int Hlth. 2010;15(1):673-91.

4. World Health Organization. Report of the thirteenth meeting of the WHO alliance for the elimination of blinding trachoma. World Health Organization, Geneva. 2-18p.

5. Bailey R, Duong T, Carpenter B, Whittle H, Mabey D. The duration of human ocular Chlamydia trachomatis infection is age dependent. Epidemiol Infect. 1999;123(3):479-86.

6. King J, Ngondi J, Gatpan G, Lopidia B, Becknell S, Emerson P. The burden of trachoma in Ayod county of southern Sudan. PLoS Negl Trop Dis. 2008;2(9):e299.

7. Kuper H, Solomon A, Buchan J, Zondervan M, Foster A, Mabey D. A critical review of the SAFE strategy for the prevention of blinding trachoma. Lancet Infect Dis. 2003;3(6):372-81.

8. West S, Congdon N, Mele L. Facial cleanliness and risk of trachoma in families. Arch Ophthal. 1991;109(6):855-7.

9. West $S$, Muñoz B, Lynch M, et al. Impact of face-washing on trachoma in Kongwa, Tanzania. Lancet. 1998;345(8943):155-8.

10. West $\mathrm{S}$, Emerson $\mathrm{P}, \mathrm{Mkocha} \mathrm{H}$, et al. Intensive insecticide spraying for fly control after mass antibiotic treatment for trachoma in a hyperendemic setting: a randomized trial. Lancet. 2006;368(9535):596-600.

11. Emerson $P$, Lindsay $S$, Walraven $G$, et al. Effect of fly control on trachoma and diarrhoea. Lancet. 1998;353(9162):1401-3.

12. World Health Organization. Trachoma Grading Card. Prevention of Blindness and Deafness. 2013. Available from http://www.who.int/blindness/ causes/trachoma_documents/en/.

13. Emerson $P$, Bailey $R$, Mahdi $O$, Walraven $G$, Lindsay $S$. Transmission ecology of the fly Musca sorbens, a putative vector of trachoma. Trans R Soc Trop Med Hyg. 2000;94(1), 28-32.

14. Burton $\mathrm{M}$, Bowman $\mathrm{R}$, Faal $\mathrm{H}$, et al. Long term outcome of trichiasis surgery in the Gambia. Br J Ophthalmol. 2005;89(5):575-9.

15. Reacher M, Foster A, Huber J. Surgical procedure. In: Reacher M, Foster A Huber J, eds. Trichiasis surgery for trachoma: the bilamellar tarsal rotation procedure. World Health Organization: Geneva. 1998.

16. Bowman R, Faal H, Jatta B, et al. Longitudinal study of trachomatous trichiasis in The Gambia: barriers to acceptance of surgery. Invest Ophthal Vis Sci. 2002;43(4):936-40.

17. Bowman R, Soma OS, Alexander N, et al. Should trichiasis surgery be offered in the village? A community randomised trial of village vs. health centre-based surgery. Trop Med Intl Health. 2002;5(8):528-33.

18. Solomon A, Holland $\mathrm{M}$, Alexander $\mathrm{N}$, et al. Mass treatment with singledose azithromycin for trachoma. N Engl J Med. 2004; 351(19):1962-71.

19. Bailey R, Arullendran P, Whittle H, Mabey D. Randomized controlled trial of single-dose azithromycin in treatment of trachoma. Lancet. 1993;342(8869):453-6.

20. Hong K, Schacter J, Moncada J, Zhou Z, House J, Lietman T. Lack of macrolide resistance in Chlamydia trachomatis after mass azithromycin distributions for trachoma. Emer Infect Dis. 2009;15(7):1088-90.
21. Bailey $R$, Lietman T. The SAFE strategy for the elimination of trachoma by 2020: Will it work? Bull World Health Organ. 2001;79(3):233-6.

22. Sutter EE, Ballard RC. Community participation in the control of trachoma in Gazankulu. Soc Sci Med. 1983;17(22):1813-7.

23. Stocks M, Ogden S, Haddad D. Effect of water, sanitation and hygiene on the prevention of trachoma: a systematic review and meta-analysis. PLos Medicine. 2014;11(2): e1001605.

24. Emerson PM, Cairncross S, Bailey RL, Mabey DC. Review of the evidence for the $\mathrm{F}$ and $\mathrm{E}$ components of the SAFE strategy for trachoma. Trop Med Int Health. 2000;5(8):515-27.

25. Emerson PM, Lindsay SW, Alexander $\mathrm{N}$, et al. Role of flies and provision of latrines in trachoma control: cluster-randomized controlled trial. Lancet. 2004;363(9415):1093-8.

26. Solomon A, Zondervan $M$, Kuper $H$, et al. Intervention. In: World Health Organization: Trachoma control: A guide for programme managers. 2006 17-40.

27. International Coalition for Trachoma Control. The end in sight: 2020 Insight. 2011. 13-27p. 